\title{
Impact of 8-Week Bedside Ultrasound Training for Surgical Residents in the Intensive Care Unit of a Tertiary Care Hospital - a Pilot Study
}

\author{
Kyoung Moo Im, Eun Young Kim ${ }^{1}$ \\ Department of Surgery, Seoul St. Mary's Hospital, ${ }^{1}$ Division of Trauma and Surgical Critical Care, Department of Surgery, \\ Seoul St. Mary's Hospital, College of Medicine, The Catholic University of Korea, Seoul, Korea
}

Received March 10, 2021

Revised April 15, 2021

Accepted April 22, 2021
Correspondence to:

Eun Young Kim

Division of Trauma and Surgical

Critical Care, Department of Surgery, Seoul St. Mary's Hospital,

College of Medicine, The Catholic

University of Korea, Banpo-daero

222, Seocho-gu, Seoul 06591,

Korea

Tel: + 82-2-2258-2876

Fax: + 82-2-595-2822

E-mail: freesshs@naver.com
Purpose: Bedside ultrasound has become one of the most important non-invasive and readily available diagnostic tools, especially for critically ill patients. Despite the increasing usage and importance of bedside ultrasound, a standard and well-structured training program for surgical residents is still lacking. This study assessed and evaluated the effectiveness of our new 8-weeks ultrasound course for surgical residents.

Methods: Twenty-two residents from the department of general surgery from a tertiary care hospital in Korea attended the newly designed 8-weeks of bedside ultrasound training course in the surgical intensive care unit. A multimodal approach was used including didactic lectures about the basics of ultrasound as well as daily hands-on ultrasound examinations of patients under the supervision of an instructor. Participants documented their ultrasound findings and determined self-proficiency in ultrasound techniques using a 5-point Likert scale.

Results: After the educational intervention, the proficiency scores of the residents showed a significant improvement in every element $(\mathrm{P}<0.001)$. Proficiency scores also showed a significant improvement regardless of their previous exposure to ultrasound manipulation. Among the most perceived barriers in using bedside ultrasound were lack of education (43\%) and lack of a feedback system (29\%).

Conclusion: The confidence of surgical residents in their use of bedside ultrasound could be improved with a well-structured training program. In addition, a short and intense program may help them to overcome the barriers that they may perceive to using bedside ultrasound. The authors believe such programs should be encouraged in all surgical residencies so that residents can competently use bedside ultrasound for the primary care of critically ill patients.

Keywords: Surgical residents, Ultrasound, Education, Barriers, Likert scale

\section{INTRODUCTION}

The use of bedside ultrasound is expending across both medical and surgical specialties. $(1,2)$ It is an effective diagnostic tool for detecting free intraperitoneal fluid in trauma patient, making a rapid diagnosis of shock etiology, or determining the fluid status in patients.(3-5) Especially in the intensive care unit (ICU), where the most of patients are immobilized and hemodynamically unstable, the bedside ultrasound is favorable due to it is noninvasive, portable in- 
struments, and expeditious in assessing the critical ill patients. $(1,6,7)$ Therefore, it would be very necessary for a resident who needs to quickly and accurately perform primary care and diagnosis for these critical ill patients. In the United States, the American College of Surgeons provided the first ultrasound course since 1996.(8,9) In case of South Korea, the Korean Society of Pediatric Emergency Medicine and Society of Emergency and Critical Care Imaging have conducted emergency ultrasound education since 2013, and they reported the significant improvement of the residents'ability to perform ultrasound after completing their education program. $(3,10)$ The Korean Surgical Society has also mandated that all residents in the general surgery attain competency in the use of ultrasound in the field of various surgeries. However, most residents still do not have sufficient practical opportunities. The reasons might be due to curricular time constraints, lack of equipment, shortage of accredited ultrasound trainers, or absence of structured educational program. $(2,11,12)$ These obstacles led most of the surgical residents having slight chance of training and little experience in using the ultrasound during their training period, consecutively. As a result, the needs for development and implementation of a formal, well-established bedside ultrasound training program have been increasing to the surgical residents who are novice in conducting the sonography.

Herein, we introduced our preliminary report using an 8 -weeks of bedside ultrasound training program that in- clude didactic lectures and direct patient scanning of the actual ICU patients. Additionally, we determine whether our training program can improve residents' skill and self-confidence in bedside sonography using the questionnaire survey and find out what are the barriers for surgical residents to perform bedside ultrasound in a real clinical setting.

\section{METHODS}

\section{Participants and methods}

In this pilot study, 22 residents from the department of general surgery at the university-based tertiary care medical center were enrolled. The participants involved 8 -weeks of bedside ultrasound training program at surgical ICU from March 2019 to August 2020. For a comprehensive bedside ultrasound training, our program consists of two different teaching methods, which are the didactic lectures and practical session with direct patient scanning. GE Healthcare LOGIQ P9 (Boston, MA) ultrasound machine was used for the training. A convex transducer (C1-5, low frequency, 2-5 MHZ) and a linear transducer (3SC, high frequency, 1.7-4 MHZ) were used for both sonographic training and assessment.

The surgeon who has specialty in trauma and surgical critical care developed the didactic presentation. Each resident received about one-hour didactic lecture every week based on the description of "Choi BI. Ultrasound Diagnosis

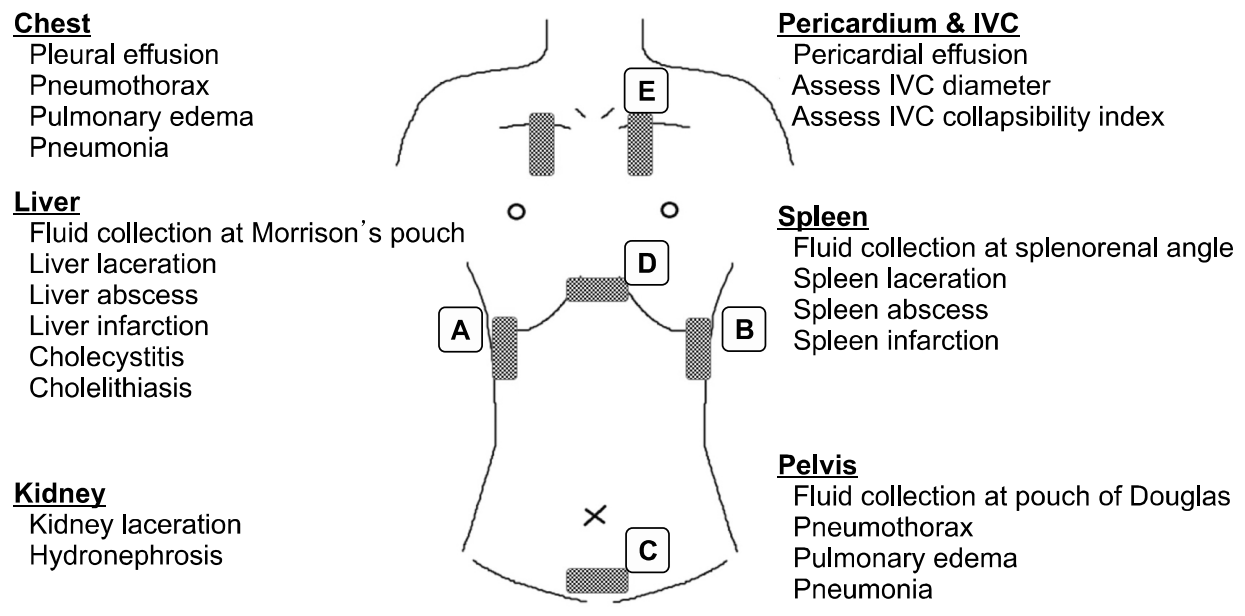

Chest

Peural effusion Pneumonia

Liver laceration

Liver abscess

Kidney

Kidney laceration
Hydronephrosis
Fig. 1. Findings to look for during hands-on session. 
of the Abdomen. 3rd ed. Ilchokak Publishers; 2015”.(13) The early lecture focused on basic physics of ultrasound, knobology, the frequency and echogenicity of ultrasound, basic modes of orientation and machine functions. The latter lecture focused on the technique of extended-Focused Assessment with Sonography in Trauma (e-FAST) and the assessment of inferior vena cava (IVC) diameter. Following the didactic portion, the hands-on sessions were introduced. Each resident went through e-FAST examination and measured IVC size on the patients in surgical ICU under instructor's supervision. For the examination, the patient was positioned supine to 30-degree upright and each resident performed focused evaluation on five different areas: chest, right upper quadrant, left upper quadrant, suprapubic and subxiphoid as shown in Fig. 1.(1,4,6,7) Each resident focus to visualize each organ (lung, liver, spleen, bladder, kidney and heart) and identify any abnormal findings such as free intraperitoneal fluid, pericardial fluid, pneumothorax, or pleural effusion. Intraperitoneal fluid was detected by examining hepatorenal space, splenorenal space, and retrovesicular spaces. Particularly in the cases of penetrating trauma, pericardium wascarefully evaluated for pericardial effusion. Finally, both thoraxes were evaluated for fluid collection above diaphragm and anterior wall for pneumothorax.

After completion of hands-on course, trainee conducted a post-course survey. Every week, participated residents completed the questionnaire to assess their own comprehension and confidence (Appendix 1) and the objective structured assessment of ultrasound skill (OSAUS) to assess their own skills (Appendix 2). Then they documented the findins of each patients (Appendix 3). All questionnaires were estimated by the score ranged from 1 to 5 , using a 5-point Likert scale ( $1=$ not confident at all, and $5=$ very confident $)$. The Likert scale is an orderly scale and a form of closed question that is most widely used tools in researching opinion or educational training for its advantage of that people are not forced to express an either-or opinion.(14-20) We queried how the residents perceived their own confidence and proficiency during examination in detail by seven different areas or organs of patient's body (lung, pleural effusion, bowel, peritoneal cavity, hepatobiliary, internal jugular vein and inferior vena cava). Furthermore, the resident's competency was also assessed using a Delphi's Objective Structured Assessment of Ultrasound Skills (OSAUS), a generic ultrasound rating scale that was achieved through international multispecialty consensus.(21) We modified and simplified the original form of OSAUS and queried on five elements: applied knowledge of ultrasound equipment, image optimization, systematic examination, interpretation of images, and documentation of examination. None of collected data could be linked to individual participants, so the results of assessment could not have any impact on assessing the individual participants' abilities that was conducted by supervisor. In this study, the primary outcome was to assess the effectiveness of our training course by measuring competency of each residents using the validated 5-point Likert scale. The secondary outcome measures were to assess whether there are differences in the efficacy of program by post-graduate year or by previous experience in bedside ultrasonography. Additionally, we evaluated the residents' obstacles in performing ultrasound examination during their clinical works.

\section{Statistical analysis}

All statistical analyses were performed using SPSS statistical package software (version 21.0 for Windows; SPSS, Inc., Chicago, IL). Survey responses to questions regarding confidence ranged from 1 (not confident at all) to 5 (very confident). We compared the demographics, previous training history, as well as other variables of residents who reported being confident in training with those who did not to assess for the differences in confidence levels. Continuous data are demonstrated as the mean \pm standard deviation and overall differences were calculated by Student's t-test or ANOVA. The Fisher's exact test or chi-square test were conducted for the categorical variables. The descriptive statistics are presented as means \pm standard deviation and differences were regarded as statistically significant when $\mathrm{P}<$ 0.05 . 


\section{RESULTS}

During the study period, 22 residents from PGY 1 to PGY 4 completed the bedside ultrasound training program at surgical ICU of our institution. Among them, only 8 participants had experienced in bedside ultrasound before the training and the distribution of trainees by postgraduate years were presented in Fig. 2; 6 trainees of PGY 1, 4 train-

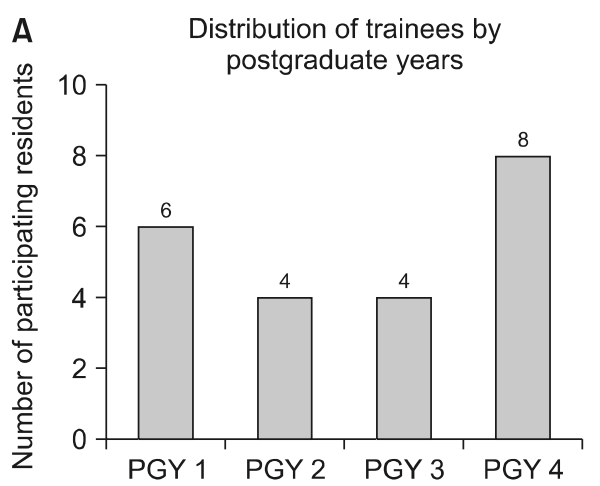

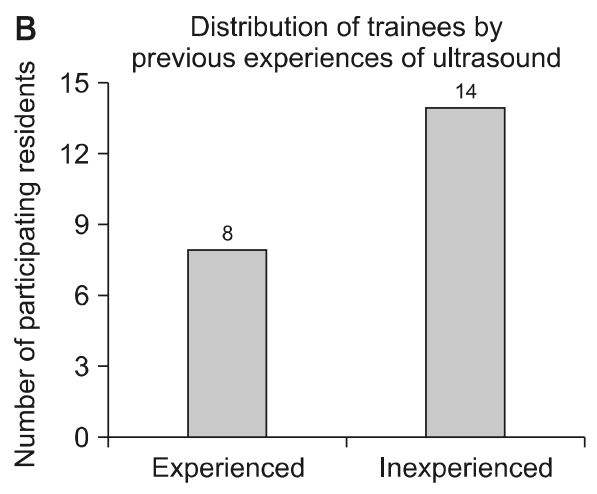

Fig. 2. Distribution of trainees by postgraduate years and by previous experience of ultrasound training.

Table 1. Demographic Characteristics of Enrolled Cases

\begin{tabular}{|c|c|c|}
\hline Variables & & $\mathrm{N}(\%)$ \\
\hline \multicolumn{3}{|l|}{ Trainee $(\mathrm{N}=22)$} \\
\hline \multirow[t]{4}{*}{ Postgraduate year } & 1 & 6 \\
\hline & 2 & 4 \\
\hline & 3 & 4 \\
\hline & 4 & 8 \\
\hline Previous experience of bedside sonogram & Yes/No & $8 / 14$ \\
\hline \multirow[t]{2}{*}{ Number of sonographic cases before training } & Experienced & 5.8 \\
\hline & Inexperienced & 0.9 \\
\hline \multicolumn{3}{|l|}{ Patient demographics $(\mathrm{N}=409)$} \\
\hline Age & & $73.5 \pm 8.3$ \\
\hline Sex & Male/Female & $265 / 144$ \\
\hline ICU HD at the time of sonogram & & $7.2 \pm 5.1$ \\
\hline \multirow[t]{6}{*}{ Clinical department } & Upper GI & $59(14.4)$ \\
\hline & Lower GI & $127(31.1)$ \\
\hline & Hepatobiliary-pancreas & $79(19.3)$ \\
\hline & Vascular & $128(31.3)$ \\
\hline & Trauma & $6(1.5)$ \\
\hline & Miscellaneous & $10(1.2)$ \\
\hline \multicolumn{3}{|l|}{ Sonographic findings $(\mathrm{N}=1,456)$} \\
\hline \multirow[t]{3}{*}{ Chest } & Pleural effusion & $360(24.7)$ \\
\hline & Pneumothorax & $10(0.7)$ \\
\hline & Pulmonary edema & $132(9.1)$ \\
\hline \multirow[t]{3}{*}{ Hepatobiliary (liver, GB, pancreas, spleen) } & Fluid collection & $129(8.9)$ \\
\hline & Mass or hematoma & $29(2)$ \\
\hline & Cholecystitis or stone, polyp & $146(10)$ \\
\hline \multirow[t]{3}{*}{ Abdomen and pelvis } & Fluid collection & $273(18.8)$ \\
\hline & Mass or hematoma & $112(7.7)$ \\
\hline & Hydronephrosis & $14(1)$ \\
\hline \multirow[t]{4}{*}{ IVC dilatation } & Normal & $677(46.5)$ \\
\hline & Collapsed & $439(30.2)$ \\
\hline & Dilated & $246(16.9)$ \\
\hline & Not checkable & $94(6.5)$ \\
\hline
\end{tabular}


ees of PGY 2, 4 trainees of PGY 3, and 8 trainees of PGY 4. The definition of an experience group is as the participants who had performed bedside ultrasound on at least five times in clinical setting prior to study enrollment. The average number of sonographic cases in the experienced group before the study enrollment was 5.8, whereas the average number of inexperienced residents group was 0.9 . In the current study, 1,456 ultrasound examinations with 409 patients were completed and analyzed. Mean age of patients was 73.5 years and most of them were from department of vascular surgery $(n=128,31.3 \%)$ and department of lower gastrointestinal surgery $(n=127,31.1 \%)$. The patient demographics and sonographic findings are presented in Table 1.

On the proficiency and OSAUS scores, there were a significant increase in their confidence level measured after the training course in all elements $(\mathrm{P}<0.001)$ compared with scores before the training (Fig. 3). Between each PGY groups, PGY 4 showed improvement in every element $(\mathrm{P}<$
0.001), whereas PGY 1 showed significant improvement in only six different items as shown in Table 2.

In Table 3, the comparative analysis of scores before and after the training course of two groups according to prior experience of ultrasound are presented in order to determine if the previous exposure to bedside sonography affect the result of training. Both groups demonstrated significantly higher confidence level after the completion of training course. Comparing the degree of advances between the two groups, experienced group demonstrated greater improvement in the proficiency score of pleural effusion showed differences ( $P<0.001)$. In OSAUS score, the experienced group also showed greater improvement in applied knowledge, interpretation of images and documentation of examination.

Fig. 4 demonstrated survey result of the barriers to using bedside ultrasound by surgical residents who participated in the study. Our results revealed that the residents think educational barrier, which are lack of proper teaching and
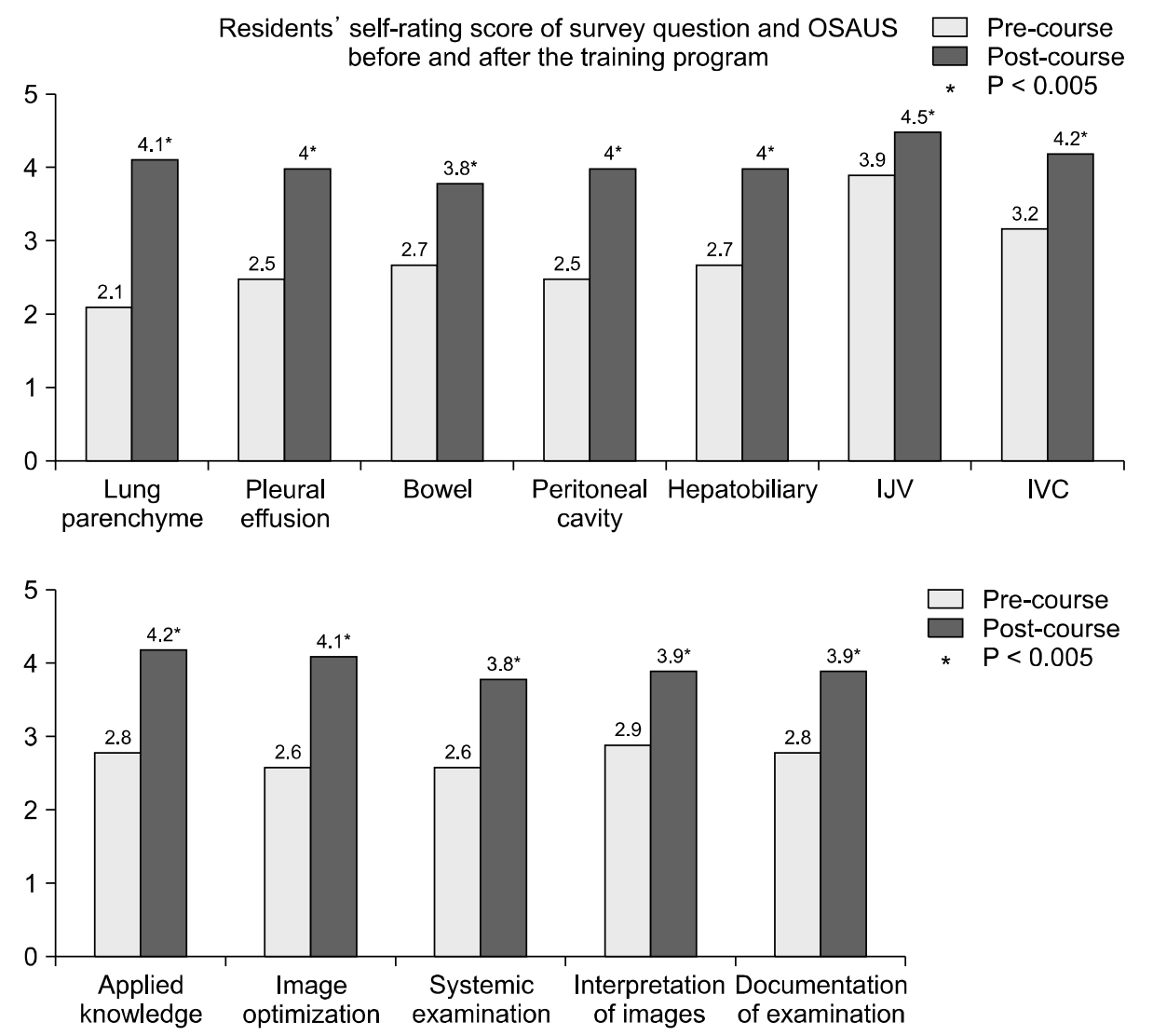

Fig. 3. Residents' self-rating score of survey question and OSAUS before and after the training program. 


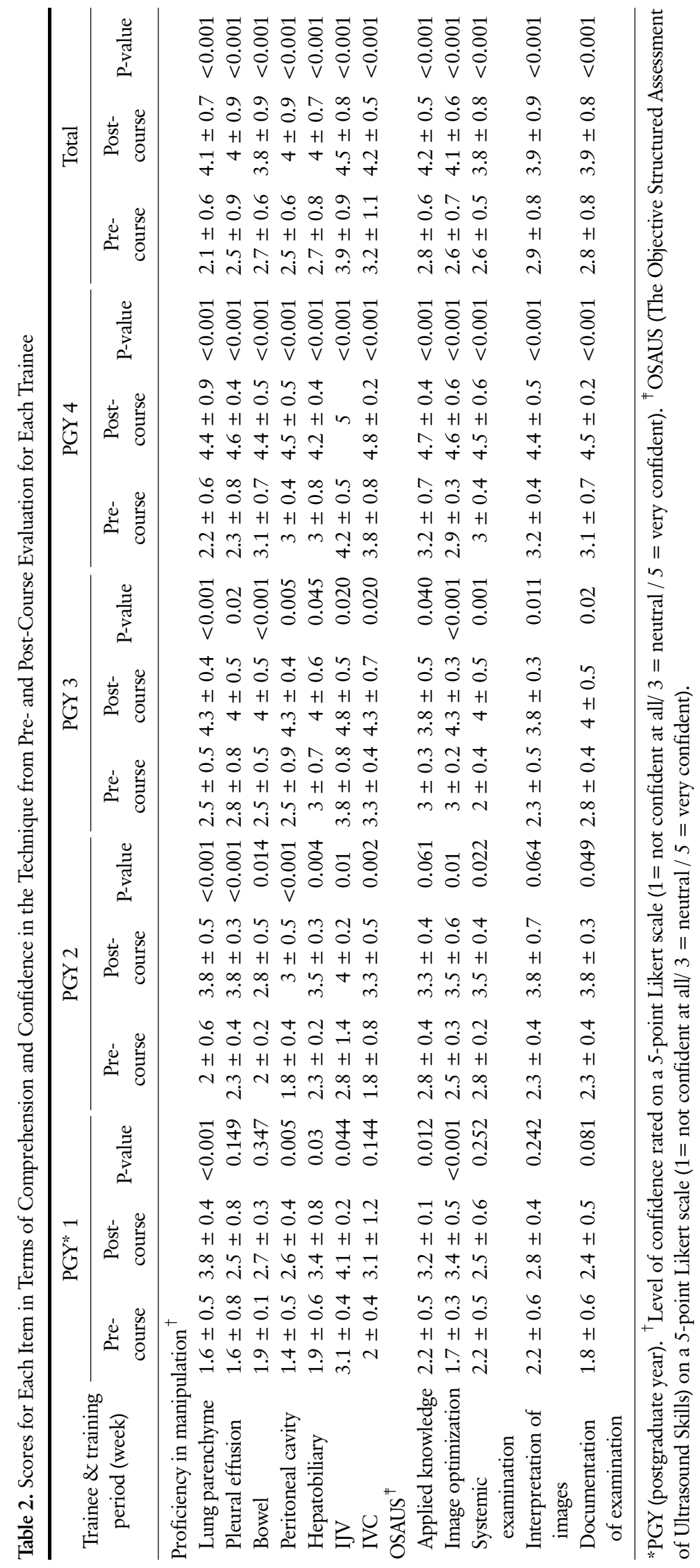


Table 3. Differences of Pre- and Post-Course Evaluation in Terms of Comprehension \& Confidence in the Technique* of Experienced and Inexperienced Residents (Average of Mean Difference)

\begin{tabular}{|c|c|c|c|c|c|c|c|}
\hline & \multicolumn{3}{|c|}{ Experienced } & \multicolumn{3}{|c|}{ Inexperienced } & \multirow{2}{*}{ P-value } \\
\hline & Pre-course & Post-course & P-value & Pre-course & Post-course & P-value & \\
\hline \multicolumn{8}{|l|}{ Proficiency in manipulation } \\
\hline Lung parenchyme & $2.1 \pm 0.6$ & $4.1 \pm 0.9$ & $<0.001$ & $2.2 \pm 0.6$ & $4 \pm 0.5$ & $<0.001$ & 0.494 \\
\hline Pleural effusion & $3 \pm 0.9$ & $4.4 \pm 0.7$ & $<0.001$ & $2.3 \pm 0.8$ & $3.4 \pm 0.7$ & $<0.001$ & $<0.001$ \\
\hline Bowel & $2.7 \pm 0.7$ & $4.2 \pm 0.5$ & $<0.001$ & $1.8 \pm 0.9$ & $3.3 \pm 0.6$ & $<0.001$ & 0.360 \\
\hline Peritoneal cavity & $2.8 \pm 0.3$ & $4.4 \pm 0.6$ & $<0.001$ & $1.7 \pm 0.8$ & $3.5 \pm 0.7$ & $<0.001$ & 0.848 \\
\hline Hepatobiliary & $2.9 \pm 0.5$ & $4.3 \pm 0.6$ & $<0.001$ & $2.3 \pm 0.8$ & $3.4 \pm 0.5$ & 0.004 & 0.372 \\
\hline IJV & $4.1 \pm 0.7$ & $4.8 \pm 0.7$ & $<0.001$ & $2.7 \pm 0.7$ & $3.6 \pm 0.4$ & 0.045 & 0.450 \\
\hline IVC & $3.6 \pm 0.8$ & $4.7 \pm 0.5$ & $<0.001$ & $2.2 \pm 0.9$ & $3.5 \pm 0.7$ & 0.002 & 0.267 \\
\hline \multicolumn{8}{|l|}{ OSAUS $^{\dagger}$} \\
\hline Applied knowledge & $3.1 \pm 0.7$ & $4.7 \pm 0.6$ & $<0.001$ & $2.5 \pm 0.6$ & $3.3 \pm 0.7$ & 0.009 & 0.002 \\
\hline Image optimization & $2.8 \pm 0.6$ & $4.1 \pm 0.8$ & $<0.001$ & $2.3 \pm 0.4$ & $3.7 \pm 0.7$ & $<0.001$ & 0.566 \\
\hline Systemic examination & $2.9 \pm 0.4$ & $4.3 \pm 0.7$ & $<0.001$ & $2.3 \pm 0.5$ & $3.6 \pm 0.5$ & $<0.001$ & 0.148 \\
\hline Interpretation of images & $3.2 \pm 0.5$ & $4.4 \pm 0.6$ & $<0.001$ & $2.3 \pm 0.6$ & $3.6 \pm 0.8$ & $<0.001$ & 0.015 \\
\hline Documentation of examination & $3.1 \pm 0.7$ & $4.2 \pm 0.6$ & $<0.001$ & $2.1 \pm 0.6$ & $3.2 \pm 0.9$ & 0.001 & $<0.001$ \\
\hline
\end{tabular}

"Level of confidence rated on a 5 -point Likert scale ( $1=$ not confident at all $3=$ neutral $/ 5=$ very confident). ${ }^{\dagger}$ OSAUS (The Objective Structured Assessment of Ultrasound Skills) on a 5 -point Likert scale $(1=$ not confident at all $/ 3=$ neutral $/ 5=$ very confident).

\section{Barriers to clinical use of bedside ultrasound by surgical residents}

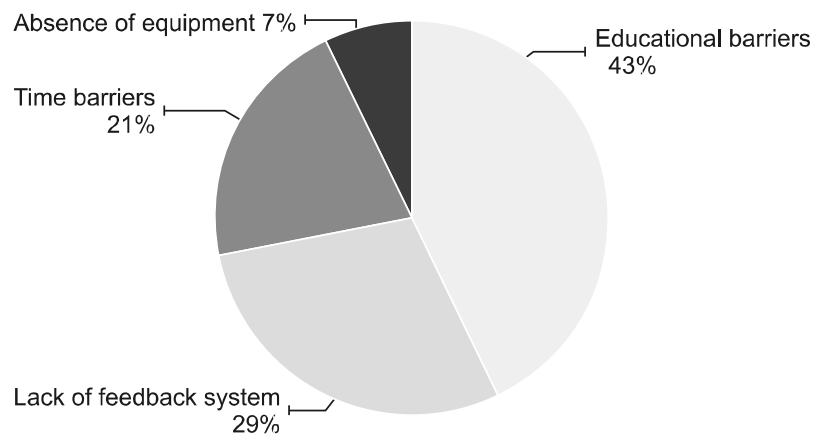

Fig. 4. Barriers to clinical use of bedside ultrasound by surgical residents.

training or inability to perform ultrasound were the greatest barriers in using ultrasound in clinical setting (43\%). Subsequently, 29\% of total respondents said that the lack of a feedback system, which should be done without appropriate supervision or assessment of senior or specialized staff, was the main obstacle. The time barriers, due to the burden of time required to start the exam, or to complete the exam during limited working hours, was responded in $21 \%$ of all respondents. $7 \%$ of all responders answered that they did not have the equipment on time, such as inability to find or use the machine.

\section{DISCUSSION}

Key aspect of ultrasound examination is that it is highly operator dependent. In ultrasound, the quality of the exam is not only depended on the equipment, but also on the skills of the operator who performs the exam.(22) Therefore, in order for the resident to perform ultrasound exam, they need to know the theoretical knowledge, able to acquire adequate images and also know how to interpret the images accurately.(23) Since ultrasound training cannot be achieve by only simulation-based learning or lectures, multimodal approach including hands-on training has been suggested.(24) For example, environment in hospital or patient's clinical setting such as pain, abdominal wounds, limitation in position causes difficulties in performing ultrasound exam, which cannot be learned through didactic lectures or simulation learning with a healthy model or a manikin. For these reasons, a comprehensive training program with a variety of educational methods should be provide to the trainees.(25)

Interestingly, as shown in Table 2, the pre-course scores 
in proficiency and OSAUS were similarly low regardless of year of training. After the course, PGY 4 showed significant improvement in every areas of evaluation. Contrary to this, PGY 1 only showed the improvement in only few areas and exhibited the lowest responses after the training program. This might be attributed to limited understanding of anatomical structure and ultrasound imaging. We believe that the senior residents have more experience in surgeries, other procedures and clinical settings that facilitate them to acquire skills more quickly and increase their confidence level in performing bedside ultrasound. We expect that our training program could be more effective to residents who have prior knowledge of ultrasound and better understanding of the patients' anatomy. In Table 3, we found both experienced and inexperienced group showed significant improvement of confidence level after the course. These results support that this training program is not only useful to novice residents, but also helps to enhance the understanding and confidence levels of the non-beginners who had only little experience of bedside ultrasound. Further collection of more objective dataand the conductance of comparative analysis between postgraduate years or between the novice and experienced residents are needed to make detail guidelines in residents' ultrasound training curriculum and structured educational program.

In educational point, the bedside sonographic examination can be easily applied by inexperienced learners, giving them a proficiency and accuracy comparable to radiologist as described in previous studies. $(2,8,26)$ However, despite these advantages, there are many challenges remain in the introduction of a formal ultrasound training curriculum to surgical residents. As shown in Fig. 4 of this study, there are several barriers to general utilization of bedside ultrasound due to lack proper training opportunities, self-confidence, time and environment. Firstly, traditional ultrasound education uses an apprenticeship approach. The senior residents or critical care attendings provided informal courses depend on their interest and expertise. There was no standardized training or any structured education of ultrasound. Therefore, without thor- ough understanding of ultrasound, basic anatomy, image acquisition skills and ability to interpretation skills, it is hard for the residents to perform bedside ultrasound. Secondly, residents do not feel that ultrasound is their scope of practice and do not have confidence to perform the exam on their own without any supervision. Consequently, residents do not feel comfortable or have confidence in performing ultrasound. Thirdly, there are restriction in resident's duty hours, so it is challenging for them to initiate or complete the exam. Lastly, not every institution has portable ultrasound machines, which can be used solely for educational purposes or surgical resident. Therefore, the machine is often in use and much time and many efforts are required to use the ultrasound machine on time. Due to these reasons, the need for easy to learn in a short period of time and well-structured educational training for wide range of surgical residents is needed. In our training program, residents can repeatedly experience bedside ultrasound during a short period of time, to patients in the surgical ICU, where most of patients have similar characteristic features such as post-operative abdominal wound, alert mental status and well cooperative patients. In addition, residents can easily approach and use other clinical information such as previous imaging or laboratory tests to make better understanding of patient's current status. Our results demonstrated that a significant improvement in overall knowledge and confidence of bedside sonography when comparing the pre- and post-course score. This improvement occurred over two months, which is relatively a short period of time. Authors expect that the well-established and systematized bedside ultrasound training program could ultimately bring the resident adequate level of confidence and proficiency of bedside ultrasound.

Despite these interesting findings, our study had inherent limitations that require caution to interpret the results. First, this study has small number of trainees and it was done in single institution, thus our result of this study cannot be generalized to other institutions. To establish the reliability and reproducibility of our results and to find if it 
can be applied to other training hospitals, the study with large number of trainees across different training hospitals should be conducted in the near future. In addition, after completing the training program, we did not verify the accuracy or the residents' ability to perform and interpret ultrasounds in clinical setting. In order to implement bedside ultrasound in medical practice, the evaluation of performance in objective tool after training is needed to assess the efficacy of training program. $(27,28)$ Moreover, unlike previous reports about the ultrasound training programs, we did not perform sonography using the simulator or healthy human model but conducted bedside ultrasound in actual patients who underwent surgeries in critical ill status. As a result, it might be not easy to find every important structure each time or to observe a normal image of uninjured organ during sonographic examination. However, despite these shortcomings, our results can give awareness of absence of surgical resident's ultrasound education and showed the systematic ultrasound training program could enhance resident's ultrasound skills and confidence, effectively. We suppose that a prospective multicenter trial with largesized participants should be conducted in the near future to confirm our results and to set a detailed guideline for training curriculum, subject and duration of training program.

\section{CONCLUSION}

We introduced that a short and intense bedside ultrasound training program could be feasible to surgical residents in order to improve their skills and confidence regardless of resident's PGY or prior experiences. Given the many benefits of bedside ultrasound, our training program would be beneficial for all surgical residencies who make diagnosis and take primary care of severely ill patient in surgical ICU.

\section{CONFLICT OF INTEREST}

The authors declare that they have no conflict of interest.

\section{DATA AVAILABILITY}

The dataset supporting the conclusions of this article is included within the article (and its additional file(s)), and can be obtained from the corresponding author on a reasonable request.

\section{COMPLIANCE WITH ETHICAL STANDARDS}

This study was approved by the Institutional Review Board of the Ethics Committee of the College of Medicine, The Catholic University of Korea. All procedures that involved human participants were performed in accordance with the 1964 Helsinki declaration and its later amendments or comparable ethical standards. Informed consent was obtained from all individual participants included in the study.

\section{REFERENCES}

1. Moore CL, Copel JA. Point-of-care ultrasonography. N Engl J Med 2011;364:749-57.

2. Schnittke N, Damewood S. Identifying and overcoming barriers to resident use of point-of-care ultrasound. West J Emerg Med 2019;20:918-25.

3. Kim DY, Lee JH, Jung JY, Kwon HS, Chang IW, Kim DK, et al. Re-evaluation of pediatric emergency ultrasound education for emergency medicine residents. J Korean Soc Emerg Med 2017:28:650-8.

4. Beggs AD, Thomas PR. Point of use ultrasound by general surgeons: review of the literature and suggestions for future practice. Int J Surg 2013;11:12-7.

5. Ghane MR, Gharib M, Ebrahimi A, Saeedi M, Akbari-Kamrani M, Rezaee M, et al. Accuracy of early rapid ultrasound in shock (RUSH) examination performed by emergency physician for diagnosis of shock etiology in critically ill patients. J Emerg Trauma Shock 2015;8:5-10.

6. Cevik AA, Noureldin A, El Zubeir M, Abu-Zidan FM. Assessment of EFAST training for final year medical students in emergency medicine clerkship. Turk J Emerg Med 2018;18:100-4.

7. Helling TS, Wilson J, Augustosky K. The utility of focused abdominal ultrasound in blunt abdominal trauma: a reappraisal. Am J Surg 2007;194:728-32; discussion 732-3.

8. Nassour I, Spalding MC, Hynan LS, Gardner AK, Williams BH. The surgeon-performed ultrasound: a curriculum to improve residents' basic ultrasound knowledge. J Surg Res 2017;213: 51-9. 
9. Rempell JS, Saldana F, DiSalvo D, Kumar N, Stone MB, Chan W, et al. Pilot point-of-care ultrasound curriculum at Harvard Medical School: early experience. West J Emerg Med 2016;17: 734-40.

10. Lee JH, Kang B, Kwon H, Kim S, Kim JY, Lee JH, et al. The experience of emergency pediatric ultrasound education course. Pediatr Emerg Med J 2014;1:34-41.

11. Kim JS, Cho YS, Kim YS, Ha YR, Kang BS, Chung HS, et al. Development of an emergency abdominal ultrasound course in Korea: 1-year experience. J Korean Soc Emerg Med 2010;21:382-7.

12. Kim BK, Cha JM, Song DS. How to revitalize the abdominal ultrasonography education program. Korean J Gastroenterol 2019;73:66-9.

13. Choi BI. Ultrasound Diagnosis of the Abdomen. 3rd ed. Seoul: Ilchokak; 2015

14. Martin JA, Regehr G, Reznick R, MacRae H, Murnaghan J, Hutchison C, et al. Objective structured assessment of technical skill (OSATS) for surgical residents. Br J Surg 1997;84: 273-8.

15. Crouch AK, Dawson M, Long D, Allred D, Madsen T. Perceived confidence in the FAST exam before and after an educational intervention in a developing country. Int J Emerg Med 2010;3: 49-52.

16. Pulijala Y, Ma M, Pears M, Peebles D, Ayoub A. Effectiveness of immersive virtual reality in surgical training- a randomized control trial. J Oral Maxillofac Surg 2018;76:1065-72.

17. Fonseca AL, Reddy V, Yoo PS, Gusberg RJ, Longo WE. Senior surgical resident confidence in performing flexible endoscopy: what can we do differently? J Surg Educ 2016:73:311-6.

18. Happel CS, Lease MA, Nishisaki A, Braga MS. Evaluating simulation education via electronic surveys immediately following live critical events: a pilot study. Hosp Pediatr 2015;5:96-100.

19. Schroll R, Smith A, Martin MS, Zeoli T, Hoof M, Duchesne J, et al. Stop the bleed training: rescuer skills, knowledge, and attitudes of hemorrhage control techniques. J Surg Res 2020;245: 636-42.

20. Carver TW. Ultrasound training in surgical critical care fellowship: a survey of program directors. J Surg Educ 2018;75: 1250-5.

21. Tolsgaard MG, Todsen T, Sorensen JL, Ringsted C, Lorentzen T, Ottesen B, et al. International multispecialty consensus on how to evaluate ultrasound competence: a Delphi consensus survey. PLoS One 2013;8:e57687.

22. Tolsgaard MG. Assessment and learning of ultrasound skills in Obstetrics \& Gynecology. Dan Med J 2018;65:B5445.

23. Celebi N, Griewatz J, Malek NP, Hoffmann T, Walter C, Muller $\mathrm{R}$, et al. Outcomes of three different ways to train medical students as ultrasound tutors. BMC Med Educ 2019;19:125.

24. Knudsen L, Nawrotzki R, Schmiedl A, Mühlfeld C, Kruschinski C, Ochs M. Hands-on or no hands-on training in ultrasound imaging: a randomized trial to evaluate learning outcomes and speed of recall of topographic anatomy. Anat Sci Educ 2018;11:575-91.

25. LoPresti CM, Schnobrich DJ, Dversdal RK, Schembri F. A road map for point-of-care ultrasound training in internal medicine residency. Ultrasound J 2019;11:10.

26. Williams RJ, Windsor AC, Rosin RD, Mann DV, Crofton M. Ultrasound scanning of the acute abdomen by surgeons in training. Ann R Coll Surg Engl 1994;76:228-33.

27. Trajkovski T, Veillette C, Backstein D, Wadey VM, Kraemer B. Resident self-assessment of operative experience in primary total knee and total hip arthroplasty: is it accurate? Can J Surg 2012;55:S153-7.

28. Arora S, Miskovic D, Hull L, Moorthy K, Aggarwal R, Johannsson $\mathrm{H}$, et al. Self vs expert assessment of technical and non-technical skills in high fidelity simulation. Am J Surg 2011;202:500-6. 


\section{Survey question}

\begin{tabular}{|c|c|c|c|c|c|}
\hline \multirow{2}{*}{ Survey question } & \multicolumn{5}{|c|}{ Answer by scoring to question } \\
\cline { 2 - 6 } & 1 & 2 & 3 & 4 & 5 \\
\hline $\begin{array}{c}\text { Rate your current competency in your } \\
\text { knowledge and skills in ultrasound. }\end{array}$ & & & & & \\
\hline Rate your current competency in each organ. & 1 & 2 & 3 & 4 & 5 \\
\hline Lung & & & & & \\
\hline Pleural effusion & & & & & \\
\hline Bowel & & & & & \\
\hline Peritoneal cavity/ascites & & & & & \\
\hline Liver/GB/spleen & & & & & \\
\hline Internal jugular vein & & & & & \\
\hline IVC & & & & & \\
\hline
\end{tabular}

* Level of confidence rated on a 5-point Likert scale

$1=$ extremely unconfident/uncomfortable $3=$ neutral $5=$ extremely confident/comfortable

Appendix 1. Survey used to evaluate trainees' comprehension \& confidence of ultrasound skills. 
II. The Objective Structured Assessment of Ultrasound Skills (OSAUS)

\begin{tabular}{|c|c|c|c|c|c|}
\hline $\begin{array}{l}\text { 1. Applied knowledge of ultrasound equipment } \\
\text { - Feel comfortable with choosing the correct } \\
\text { probe of the exam, can choose correct } \\
\text { orientation of the probe and operating } \\
\text { the ultrasound. }\end{array}$ & $\begin{array}{l}1 \square \\
\text { Unable to } \\
\text { operate } \\
\text { equipment }\end{array}$ & $2 \square$ & $\begin{array}{l}\quad 3 \square \\
\text { Operates } \\
\text { the equipment } \\
\text { with some } \\
\text { experience }\end{array}$ & $4 \square$ & $\begin{array}{l}\quad 5 \square \\
\text { Familiar with } \\
\text { operating the } \\
\text { equipment }\end{array}$ \\
\hline $\begin{array}{l}\text { 2. Image optimization } \\
\text { - Feel comfortable adjusting the gain, depth focus } \\
\text { and frequency to maximize picture quality. }\end{array}$ & $\begin{array}{l}1 \square \\
\text { Fails to } \\
\text { optimize } \\
\text { images }\end{array}$ & $2 \square$ & $\begin{array}{l}\quad 3 \square \\
\text { Competent } \\
\text { image } \\
\text { optimization } \\
\text { but not done } \\
\text { consistently }\end{array}$ & $4 \square$ & $\begin{array}{l}\quad 5 \square \\
\text { Consistent } \\
\text { optimization } \\
\text { of images }\end{array}$ \\
\hline $\begin{array}{l}\text { 3. Systemic examination } \\
\text { - Approach and visualize every view } \\
\text { (subcostal, right upper quadrant, left upper } \\
\text { quadrant, pelvis, chest, IVC) systemetically and } \\
\text { present relevant structures according to } \\
\text { guidelines. }\end{array}$ & $\begin{array}{l}1 \square \\
\text { Unsystematic } \\
\text { approach }\end{array}$ & $2 \square$ & $\begin{array}{l}3 \square \\
\text { Displays some } \\
\text { systemic } \\
\text { approach }\end{array}$ & $4 \square$ & $\begin{array}{l}5 \square \\
\text { Consistently } \\
\text { displays } \\
\text { systemic } \\
\text { approach }\end{array}$ \\
\hline $\begin{array}{l}\text { 4. Interpretation of images } \\
\text { - Feel confidence in interpreting the findings and } \\
\text { recognizing image pattern. }\end{array}$ & $\begin{array}{l}1 \square \\
\text { Unable to } \\
\text { interpret any } \\
\text { findings }\end{array}$ & $2 \square$ & $\begin{array}{l}3 \square \\
\text { Does not } \\
\text { consistently } \\
\text { interpret } \\
\text { findings } \\
\text { correctly } \\
\end{array}$ & $4 \square$ & $\begin{array}{l}5 \square \\
\text { Consistently } \\
\text { interprets } \\
\text { findings } \\
\text { correctly }\end{array}$ \\
\hline $\begin{array}{l}\text { 5. Documentation of examination } \\
\text { - Discribe examination findings, using appropriate } \\
\text { anatomic and terminology. }\end{array}$ & $\begin{array}{c}1 \square \\
\text { Does not } \\
\text { document } \\
\text { any images }\end{array}$ & $2 \square$ & $\begin{array}{l}3 \square \\
\text { Documents } \\
\text { most relevant } \\
\text { images }\end{array}$ & $4 \square$ & $\begin{array}{c}5 \\
\text { Consistently } \\
\text { documents } \\
\text { relevant images }\end{array}$ \\
\hline
\end{tabular}

Appendix 2. Survey used to evaluate trainees' Objective Structured Assessment of Ultrasound Skills. 


\begin{tabular}{|c|c|c|c|c|c|c|c|}
\hline \multicolumn{8}{|c|}{ Documentation of Ultrasound } \\
\hline \multicolumn{2}{|c|}{ Date of Exam } & & & & Ultrasonographer & & \\
\hline Name & Patient No. & Sex/Age & ICU HD & POD & Diagnosis & \multicolumn{2}{|c|}{ Operation title } \\
\hline \multicolumn{8}{|l|}{$\begin{array}{c}\text { Relevant } \\
\text { history }\end{array}$} \\
\hline & & \multicolumn{6}{|c|}{ Findings } \\
\hline \multirow{2}{*}{\multicolumn{2}{|c|}{ Chest }} & \multicolumn{6}{|c|}{$\square$ Pleural effusion (Lt. / Rt.) } \\
\hline & & \multicolumn{6}{|l|}{ Others: } \\
\hline \multirow{4}{*}{\multicolumn{2}{|c|}{$\begin{array}{l}\text { Volume } \\
\text { assessment }\end{array}$}} & \multicolumn{6}{|c|}{$\square$ IVC (collapse / dilatation): $\max \_$_ $\mathrm{cm}, \min \_\mathrm{cm}$} \\
\hline & & \multicolumn{6}{|c|}{$\begin{array}{l}\square \text { VC collapsibility index }(+): \\
\{(\text { max diameter }- \text { min diameter }) /(\text { mean diameter })\} \times 100(\%)(\text { Check if }>50 \%)\end{array}$} \\
\hline & & Othore. & & & SCVO2 & 1 ontat & \\
\hline & & Uners. & & & SVO2 & Lactate & \\
\hline \multirow{4}{*}{\multicolumn{2}{|c|}{ Liver, spleen }} & \multicolumn{6}{|c|}{$\square$ Fluid collection (liver / spleen) } \\
\hline & & \multicolumn{6}{|c|}{$\square$ Mass or abscess or hematome (liver / spleen) } \\
\hline & & \multicolumn{6}{|c|}{$\square$ Cholecystitis or GB empyema } \\
\hline & & \multicolumn{6}{|l|}{ Others: } \\
\hline \multirow{3}{*}{\multicolumn{2}{|c|}{ Pelvis }} & \multicolumn{6}{|c|}{$\square$ Fluid collection (Lt. / Rt. / pelvis) } \\
\hline & & \multicolumn{6}{|c|}{$\square$ Mass or abscess or hematome (Lt. / Rt. / pelvis) } \\
\hline & & \multicolumn{6}{|l|}{ Others: } \\
\hline \multicolumn{2}{|c|}{ Other findings } & & & & & & \\
\hline
\end{tabular}

Appendix 3. Checklist for the e-FAST and IVC volume assessment ultrasound. 